\title{
Different Digital Image Processing Methods for Remote Sensing Applications
}

\author{
Derya Maktav $^{1} \cdot$ Süha Berberoglu ${ }^{2}$
}

Published online: 16 August 2018

(C) Indian Society of Remote Sensing 2018

This Special Issue presents papers focusing on different new image processing algorithms for remote sensing applications.

This Special Issue 'different digital image processing methods for remote sensing applications' features selected papers. 12 papers out of 160 invited papers, have been peer-reviewed twice and selected for the ISRS Special Issue:

- Accuracy assessment of Pleiades-1 stereo/tri-stereo digital surface models: A case-study for citrus trees (Ok, Ali, Ö.; Ok, Aslı, Ö.; Başeski, E.)

- A new sebal approach modified with backtracking search algorithm for actual evapotranspiration mapping and on-site application (Atasever, Ü,H.; Özkan, C.)

- An extended approach of particle swarm optimization for shoreline extraction from RASAT imagery (Reis, H.Ç; Bayram, B; Bozkurt, S.; İnce, A.; Demir, N.; Şeker, D.Z.)

- Selection of optimal object features in object-based image analysis using filter-based algorithms (Çölkesen, İ.; Kavzoğlu, T.)

- Comparative analyses of the point cloud produced by using close-range photogrammetry and terrrestrial laser scanning for rock surface (İncekara, A.H.; Şeker, D.Z.)

- A cloud removal algorithm to generate cloud and cloud shadow free images using information cloning (Kaan, K.; Maktav, D.)

Derya Maktav

maktavd@itu.edu.tr

Süha Berberoglu

suha@cu.edu.tr

1 Faculty of Civil Engineering, Geomatics Engineering Department, Istanbul Technical University, 34469 Istanbul, Turkey

2 Landscape Architecture Department, Cukurova University, 01330 Saricam, Adana, Turkey
- Automated detection of 3D roof planes from LIDAR data (Demir, N.)

- The prediction success responses of landslide susceptibility maps under different landslide sampling strategies (Tekin, S.; Çan, T.)

- The relationship of urban expansion, landscape patterns and ecological processes in Denizli, Turkey (Tağıl, S.; Görmüş, S.; Cengiz, S.)

- Dimensionality reduction and classification of hyperspectral images using object-based image analysis (Kavzoğlu, T.; Tonbul, H.; Erdemir, M. Y.; Çölkesen, I.)

- Mapping urban growth and its relation to sismic hazards in Istanbul (Uysal, C.; Maktav, D.; Small, C.) (RSGIS-118)

- A new semi-supervised classification method based on mixture model clustering for classification of remotely sensed multispectral image data (Göğebakan, M.; Erol, H.)

These papers focus on various methods and applications of remote sensing by diverse disciplines including geomatics, photogrammetry, mathematics, geology, landscape planning, digital image processing, etc. These different methods and applications are summarised as below:

Ok et al. assessed the quality of the digital surface model (DSM) generated from Pleiades-1 tri-stereo images to detect citrus trees through height information. In this study three methods were tested on stereo/tri-stereo images including (a) local methods (correlation-based and least squares method), (b) semi-global method (semi-global matching (SGM)), and (c) global method (SIFT-ow).

Atasever and Özkan used "surface energy balance algorithm for land (SEBAL)" for actual evapotranspiration mapping. This paper improved SEBAL-based approach, which can automatically perform hot-wet pixel selection using backtracking search algorithm (BSA) with ground control points.

Reis et al. presented an extended shoreline detection approach from pansharpened images of Turkish RASAT 
remote sensing satellite. The proposed shoreline extraction system included simple linear clustering (SLIC) and particle swarm optimization (PSO).

Çölkesen and Kavzoğlu applied three filter-based feature selection algorithms, namely Chi square, information gain and ReliefF to determine the most effective object features that ensure high separability among landscape features. Support vector machine, random forest and nearest neighbour classifiers were all utilized to classify segmented image objects using the selected object features. Results revealed that the feature selection algorithms were effective for selecting the most relevant features.

İncekara and Şeker investigated point cloud production by means of photographs rather than point cloud derived from laser scanner device. Analyses results showed that point clouds in both cases were similar.

Kalkan and Maktav detected cloud and cloud shadow features in satellite images accurately. In this study, an automated cloud removal algorithm to generate cloud and cloud shadow free images from multitemporal Landsat- 8 images was introduced.

Demir derived vectoral 3D roof planes from the LIDAR point cloud. The RANSAC algorithm was used for segmentation of LIDAR point cloud. Detection of roof planes was improved with the use of this refinement method.

Tekin and Çan assessed landslide susceptibility using logistic regression. The results showed that the susceptibility maps produced using the random selections considering the entire landslide polygons have higher prediction and success rates.
Tağıl et al. explored the temporal and spatial heterogeneity occurrence due to human intervention in landscape pattern and processes in and around a city. This study demonstrated the potential of remote sensing, GIS and landscape metrics in understanding of urban dynamics and ecosystem changes.

Kavzoğlu et al. used AVIRIS hyperspectral data and analysed the effects of high dimensional data with limited samples on the results of pixel- and object-based classifications. Nearest neighbour (NN) and random forest (RF) classifiers were employed to test the performances of pixeland object-based classification.

Uysal et al. used Landsat and DMSP night lights data to map changes in land use/cover in and around Istanbul since 1984. Changes in land use and intensity of development are identified by changes in night light brightness while changes in land cover are identified by changes in land surface reflectance.

Göğebakan and Erol introduced a new semi-supervised method for image classification. This method consists of unsupervised clustering and supervised classification of clusters using spectral signatures.

The guest editors would like to thank the authors who submitted their high-quality papers. Also, special thanks go to all the reviewers of this Special Issue, who helped in completing it in a short time. 